\title{
Professor universitário: percepções acerca das demandas e recursos de seu trabalho
}

\section{Higher education teacher: perceptivos about the demands and resources of your work}

Paula Andréa Prata-Ferreira1, Ione Vasques-Menezes², Clarissa Pinto Pizarro de Freitas $^{3}$

\section{RESUMO}

Esta pesquisa teve como objetivo investigar as percepções dos professores universitários sobre a reestruturação de seu trabalho e suas implicações para sua vida laboral e pessoal. Para tal, o estudo ancorou-se na Teoria de Demandas e Recursos (JD-R). Trata-se de uma pesquisa qualitativa, onde a análise dos dados, das seis entrevistas semiestruturadas, foi realizada no software Iramuteq, através da Análise de Similitude. Os resultados sugerem que organização do trabalho tem levado a desgastes pelo desequilíbrio entre demandas e recursos. Porém, a utilização de recursos (do trabalho e pessoais), ações de redesenho do trabalho e o sentido do trabalho são importantes fatores para diminuir demandas e proteger a saúde docente.

Palavras-chave: Professor universitário. Redesenho do Trabalho. Teoria das Demandas e Recursos do Trabalho. Condições de Trabalho.

\section{ABSTRACT}

This research aimed to investigate higher education teacher's perceptions about the restructuring of their work and its implications for their working and personal life. To this end, the study was based on the Theory of Demands and Resources (JD-R). This is a qualitative research, where the data analysis, from the six semi-structured interviews, was performed using the Iramuteq software, through Similitude Analysis. The results suggest that work organization has led to wear and tear due to the imbalance between demands and resources. However, the use of resources (work and personal), job crafting actions and the meaningful work are important factors to reduce demands and protect teacher health.

Keywords: Higher education teacher. Job Crafting. Job demands-resources theory. Meaningful Work. Job Condicions.
Mestre em Psicologia Social. Professora da Universidade Estácio de Sá

E-mail: paulaprata@gmail.com

Doutora, Professora do Programa de Pós-graduação da Universidade Salgado de Oliveira.

3 Doutora. Professora da Pontifícia Universidade Católica do Rio de Janeiro. 


\section{INTRODUÇÃOO}

O mundo do trabalho configura-se um amplo campo de pesquisas para diversas áreas, que estudam como características pessoais e do trabalho podem impactar no bemestar emocional, psicológico e social, na motivação, engajamento e no adoecimento dos trabalhadores (CARLOTTO et al., 2015; FERREIRA, 2014; SCHÖNFELD et al., 2016). A Teoria das Demandas e Recursos do Trabalho (Job Demand-Resources Theory, JD-R) de Demerouti et al. (2001) procura pesquisar de que forma recursos pessoais e do trabalho, como também demandas do trabalho podem ter impacto direto ou indireto no bem-estar dos trabalhadores (BAKKER; DEMEROUTI, 2014; SCHAUFELI; TARIS, 2014).

Os recursos pessoais são características do indivíduo que possibilitam ter gerência e impacto sobre seu ambiente de forma a alcançar desfechos bem-sucedidos. A autoeficácia é um dos recursos mais investigados na literatura (SCHAUFELI; TARIS, 2014).

As demandas do trabalho referem-se ao desgaste de recursos físicos e mentais do trabalhador que, por sua vez, podem levá-lo ao esgotamento, como também a problemas de saúde, pois acarretam custos físicos e psicológicos. Assim, as demandas representam as condições desfavoráveis no ambiente de trabalho como, por exemplo, de que maneira a carga de trabalho é distribuída e exigida, como também a ambiguidade de papéis (CRAWFORD; LEPINE; RICH, 2010).

Uma maneira de dirimir os impactos das demandas e proteger a saúde do trabalhador é ter recursos do trabalho, uma vez que os recursos conduzem o indivíduo ao melhor desempenho em suas atividades. A autonomia (grau de controle sobre o próprio trabalho), apoio dos colegas, como também o feedback são exemplos de recursos do trabalho (DEMEROUTI et al., 2001).

Mesmo que as demandas do trabalho tenham características estressoras, existem demandas que colaboram para o crescimento e aprimoramento do trabalhador. São as demandas desafiadoras. Porém, existem demandas que prejudicam o desenvolvimento pessoal, a aprendizagem e o alcance de objetivos. Nesse caso, trata-se de demandas de obstáculo (BAKKER; DEMEROUTI, 2014; CRAWFORD; LEPINE; RICH, 2010).

A proatividade dos trabalhadores em criar ações de trabalho adequadas às próprias necessidades e interesses é chamada de redesenho do trabalho. Esse conceito foi divulgado por (WRZESNIEWSKI; DUTTON, 2001) em um artigo seminal sobre o tema e posteriormente integrado ao modelo JD-R (BAKKER; DEMEROUTI, 2013). O redesenho 
do trabalho não é um evento isolado, mas sim um processo, pois envolve diversas ações psicológicas, sociais e físicas, sendo o trabalhador o protagonista (WRZESNIEWSKI; DUTTON, 2001). Assim sendo, os recursos, as ações de redesenho no trabalho e as demandas do trabalho são temas de interesse em pesquisas que procuram esclarecer de que forma esses construtos influenciam a vida do trabalhador, como também o contexto organizacional ao qual ele faz parte (BAKKER; DEMEROUTI, 2013, 2018; SCHAUFELI, 2016, 2017).

Desde a década de 90, transformações significativas marcaram as mudanças ocorridas no ensino superior presencial do Brasil, sendo impulsionadas pela Lei de Diretrizes e Bases da Educação Nacional (Lei o. 9.394, de 20 de dezembro de 1996), pelo Programa de Apoio a Planos de Reestruturação e Expansão das Universidades Federais - REUNI (Decreto № 6.096, de 24 de abril de 2007) e pelo Plano Nacional de Educação - PNE (2010). Entre outras questões, foi estimada a elevação do número de vagas para discentes e a criação de unidades no interior dos Estados.

Em relação às instituições de ensino superior (IES) privado o governo federal instituiu o Programa Universidade para Todos (PROUNI) (Lei no 11.096, de 13 de janeiro de 2005). O programa foi a oportunidade de expansão do número de vagas, como também uma saída para o preenchimento de matrículas ociosas, uma vez que crescia o número de vagas não preenchidas por estudantes sem recursos financeiros para suportar mensalidades (HAAS; PARDO, 2017; SOUZA; MENEZES, 2014).

Em termos práticos, as instituições de nível superior não se mostraram com a infraestrutura necessária para abarcar a reestruturação pretendida. Não foi previsto, por exemplo, a capacidade de absorção (ou falta dela) em relação ao corpo docente e, consequentemente, a necessidade de abertura de vagas para novos professores. Assim, a falta de recursos em dissonância com o aumento de demandas se refletiu no trabalho e na saúde do professor (DALAGASPERINA; KIELING MONTEIRO, 2016; SOUZA et al., 2017). Ou seja, as transformações que afetaram o mundo do trabalho das IES produziram resultados para a vida profissional e pessoal do professor universitário e, consequentemente, afetaram sua saúde.

Baseado na teoria JD-R, o presente trabalho tem por objetivo investigar a percepção do professor universitário sobre a reestruturação de seu trabalho e suas implicações para sua vida laboral e pessoal. Para tal, explorou-se a compreensão do professor acerca dos recursos (pessoais e do trabalho), demandas, investimentos para 
redesenho do trabalho e suas percepções sobre o sentido de seu trabalho.

\section{METODOLOGIA}

Tratou-se de uma pesquisa foi qualitativa com delineamento exploratório e descritivo. A participação dos professores universitários foi voluntária e a expressão de concordância foi realizada com a assinatura do Termo de Consentimento Livre e Esclarecido (TCLE). Os participantes tinham toda a liberdade de desistir a qualquer tempo. Em conformidade com as instruções do Comitê de Ética e Pesquisa (CEP), Resolução № 466/2012, do Conselho Nacional de Saúde, as informações colhidas e submetidas à análise, tinham probabilidade mínima de identificação. O presente projeto foi submetido e aprovado pelo CEP - Plataforma Brasil com CAAE 65103317.6.0000.5289.

Como critério de participação, o professor deveria estar em exercício efetivo em alguma instituição IES. Realizadas em janeiro de 2018, as entrevistas foram semiestruturadas seguindo um roteiro de entrevista. Os participantes, três mulheres e três homens, tinham idades entre 31 e 66 anos $(M=49,83$; $D P=13)$, onde cinco eram solteiros/divorciada/viúvo e um casado. Em relação a localização, dois trabalhavam em instituições da região metropolitana do Rio de Janeiro (um em IES pública e um em IES privada) e quatro no interior do Estado (dois em IES pública e dois em IES privada).

A experiência na docência universitária variou entre seis e doze anos $(M=7,6)$, sendo que, anterior à docência universitária, cinco lecionaram no ensino básico e apenas um exerceu cargo técnico. Metade dos professores trabalhavam em instituições públicas, mas todos trabalharam em instituições privadas anteriormente. Os professores declararam trabalhar em regime de dedicação exclusiva ou $40 \mathrm{~h}$, excetos um deles, vinculado a IES privada como horista e que ainda acumulava com a docência para o ensino básico. Em relação a titulação, a pesquisa contou com dois doutores, três mestres (um deles em doutoramento) e um especialista (cursando mestrado). Sobre a área de conhecimento, cinco atuavam na área de ciências exatas e da terra e um em ciências humanas.

A interpretação dos relatos dos participantes foi realizada por meio por meio da análise textual. A análise textual foi realizada através do software IRAMUTEQ. As seis entrevistas foram gravadas, transcritas (degravadas) e, por fim, reunidas em um único corpus para a análise de similitude. Essa análise objetiva encontrar as coocorrências 
entre as palavras e identificar a conexidade entre elas. Tal processo promove 0 reconhecimento da estrutura de representação, diferenciando partes em comum e particularidades (MARCHAND; RATINAUD, 2012). Através de uma ilustração semelhante às ramificações de uma árvore, o relatório resultante mostra a estruturação dos dados subjetivos para análise (CAMARGO; JUSTO, 2013).

\section{RESULTADOS E DISCUSSÃO}

A árvore de similitude mostrou os termos que formaram o centro de distribuição da composição que, por sua vez, estabeleceram as conexões com outros termos da distribuição (Figura 1). O principal termo foi "professor universitário" e, a partir dele foram geradas os caminhos e conexões para interpretação desse corpus.

O leque semântico foi formado por oito núcleos de convergência, onde o principal foi (1) Professor Universitário com o próprio termo "professor universitário" repetido 333 vezes. Ligados diretamente a ele, encontram-se os núcleos (2) Trabalho, (3) Trajetória Profissional, (4) Atuação e (5) Conflito. Ligado ao núcleo (5) Conflito encontra-se (6) Alicerce Docente. O núcleo (4) Atuação encontra-se entre (1) Professor Universitário e (7) Relação Docente-Discente que, por sua vez, relaciona-se com (8) Sentido do Trabalho Docente.

O núcleo (1) Professor Universitário reflete a "vida" ( $n=25)$ cotidiana do professor. É nela onde seu trabalho "acontece" ( $n=26)$ e é central em sua vida. Isso fica claro na fala do professor (P04): A minha própria vida está estruturada em cima do meu trabalho.

O trabalho do professor universitário é ancorado no tripé ensino, pesquisa e extensão. Mas, geralmente, acaba ampliado com o acúmulo de alguma "função de chefia ou coordenação" ( $n=37$ ). Em meio a esta realidade, o trabalho do "professor universitário" "acontece" vinculado a uma atarefada agenda delimitada em "dias" $(n=46)$ e "meses" ( $n=26)$, como mostrado na fala de (P07): Fico cansado... Você vai, vai trabalhando ... Você tem que estar atento. Tem os dias de ir às reuniões...

É possível perceber que o acúmulo de funções pode gerar demandas como sobrecarga física, como também conflito de papeis, uma vez que o professor se vê dividido para atender a diferentes exigências. Ressalta-se, ainda, os desfechos negativos (BAKKER; DEMEROUTI; SANZ-VERGEL, 2014) para a saúde do professor (DALAGASPERINA; KIELING MONTEIRO, 2016; SOUZA et al., 2017), pois é neste "acontecer" da "vida" laboral acadêmica que o trabalho intensificado e precarizado não 
encontra recursos suficientes para reduzir demandas de obstáculo e, consequentemente, proteger a saúde do professor, como sugerem as falas a seguir:

(P01): Sou feliz fazendo isso. Mas, quero parar, tirar um tempo para mim, para minha vida. Mas eu não consigo. Eu não consigo tempo. Eu acabo doente.

(P03): Sobrecarga. Sobrecarga no professor. Eu não aceitei ser coordenador.

(P07): É uma carga de trabalho.... São as reuniões dos colegiados. Eu, como coordenador, obrigatoriamente tenho que ir. Faz parte do pacote do coordenador.

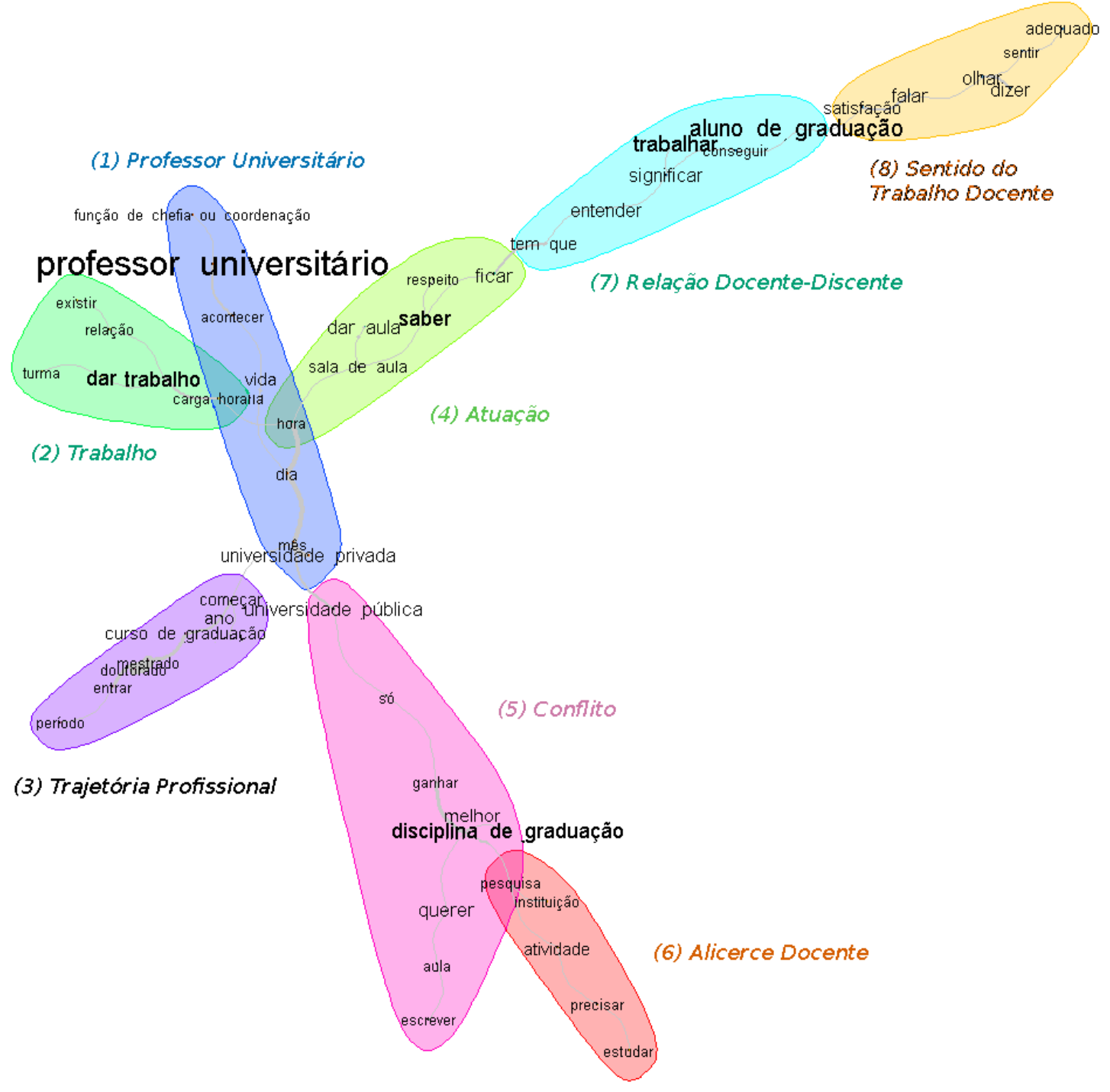

Figura 1: Análise de similitude. (Fonte: produzida pelos autores)

Segundo a Teoria JD-R (BAKKER; DEMEROUTI, 2017), recursos (pessoais e do trabalho) podem fazer com que este "acontecer" seja conduzido para possíveis desfechos favoráveis. Assim, temos que a autoeficácia ocupacional refere-se à percepção do 
trabalhador sobre sua própria capacidade e habilidade em desenvolver seu trabalho com sucesso (RIGOTTI; SCHYNS; MOHR, 2008). Nesse sentido, é possível compreender a autoeficácia ocupacional como um recurso pessoal que pode promover um melhor "acontecer" para a "vida" laboral do "professor universitário", como pode ser visto na fala do professor (P03): Se tiver que sair daqui por insatisfação, eu saio. Mas, eu tenho a certeza que eu vou para outra universidade e vou ser capaz de fazer acontecer na outra universidade.

Estudos anteriores sugerem que o redesenho do trabalho pode contribuir para melhor adequação do indivíduo à sua atividade laboral, fazendo com que ele sinta seu trabalho como significativo (TIMS; DERKS; BAKKER, 2016), como também pode promover um impacto positivo no engajamento e no desempenho do trabalho (VAN WINGERDEN; DERKS; BAKKER, 2017).

Nesse contexto e dentro dos limites da estrutura organizacional acadêmica, notouse comportamentos de redesenho do trabalho nos relatos dos professores. Assim, seja de forma a otimizar recursos e demandas do trabalho, seja para tornar o trabalho significativo e alinhado aos próprios valores, interesses e motivações docentes, foram identificados comportamentos proativos que visaram a reconfiguração da rotina acadêmica, como fica evidenciado na fala do professor (P07): Orientação? Como estou na coordenação, fico sobrecarregado de trabalho, então eu faço no máximo a orientação de trabalho de final de curso que é o TCC.

Segundo Contreras (2012), a autonomia é propriedade do fenômeno educativo e não somente uma característica profissional, sendo algo vinculado implicitamente à docência. Os professores sugerem que a autonomia é percebida como um recurso do trabalho primordial, como dito por (P04): Hoje eu tenho autonomia. Me incomodaria muito não ter. Já trabalhei em outro lugar que não tinha. Foram dias muito difíceis.

Porém, nem todos os professores conseguem ter a autonomia que necessitam para o exercício de sua função. Os professores sugerem que, como dito por (P02) abaixo, a falta de autonomia é percebida como resultante da sobrecarga e das políticas gerencialistas empregadas. Tal associação não surpreende, pois, pautada nas transformações ocorridas nas últimas décadas, a educação superior tem deixado de ser um bem de direito para ser um bem de serviço (MAGALHÃES, 2013). Ademais, uma vez latente ao exercício da docência (CONTRERAS, 2012), a autonomia, quando escassa ou 
ausente, tem sido associada a desfechos negativos para a saúde do professor (DALAGASPERINA; KIELING MONTEIRO, 2016; SOUZA; SANTOS; ALMEIDA, 2016).

(P02): Lá, os professores, além de pressionados com ementas e prazos loucos, têm uma coisa assim: você tem que dar o exemplo 1 e 2, mandar pra casa o 4 e 5 . Se você mandar até o 6, alguém vai reclamar e chamar sua atenção..., mas o professor é ou não é você, caramba! Aí você fica completamente amarrado. Seria um trabalho que eu ficaria incomodado.

O núcleo (2) Trabalho liga-se ao núcleo (1) Professor Universitário através de "carga-horária". A "carga-horária" é um elemento concreto na dinâmica laboral do "professor universitário" e onde ele apoia o desenvolvimento de seu "trabalho".

É possível perceber duas vias vinculadas ao termo "trabalho": uma iniciada em "turma" e a outra em "existir". Na relação "turma $(n=26)$ - dar $(n=108)$ - trabalho $(n=112)$ carga-horária $(n=56)$ " os professores mostraram maior satisfação com suas condições atuais de trabalho. Uma das possíveis razões seria pelo fato de que, até ingressarem no ensino superior, cinco dos seis professores trabalharam anteriormente no ensino básico e, por isso, conheceram as condições que comprometem o desenvolvimento do trabalho docente. Além disso, a carga-horária de um professor universitário com dedicação exclusiva, por exemplo, prevê vinte horas semanais para estudos, pesquisa, trabalhos de extensão, planejamento e avaliação. Tal rotina não existe no ensino básico, sem contar com o abismo salarial e social entre ambos. Assim, mesmo reconhecendo as demandas que permeiam a vida do professor universitário, as falas sugerem, como a do professor (P03), que os recursos vivenciados na docência superior são superiores quando comparados ao ensino básico: Quando eu cheguei na universidade, e eu já trabalhei em cinco, eu me vi muito mais livre, valorizado, mais bem remunerado, com mais qualidade de trabalho.

Ainda no núcleo (2) Trabalho, no eixo "existir ( $n=29)$ - relação ( $n=34)$ - trabalho ( $n=112)$ - carga-horária ( $n=56)$ ", a relação do termo "existir" sugere uma referência as demandas de obstáculo, como sobrecarga e demandas de relacionamento. Isso pode ocorrer, por exemplo, quando, na relação professor-aluno em IES privadas, o discente não se encontra no papel de aluno, mas sim de cliente, como evidenciado na fala de (P01): Existe muita pressão... essa relação estabelecida entre a docência e o corpo discente como uma relação de negócio é muito ruim. O professor fica oprimido. 
P. P.

Professor universitário: percepções acerca das demandas e recursos de seu trabalho

O núcleo (3) Trajetória Profissional descreve a trajetória profissional do professor até alcançar à docência universitária. Ela relaciona-se com o núcleo central (1) Professor Universitário com o elo entre "começar" e "universidade privada". Essa relação pode ser explicada pelo fato de que os professores entrevistados iniciaram a carreira como docentes de ensino superior em IES privadas. Assim, o eixo "começar $(n=43)$ - ano ( $n=77)$ - curso de graduação ( $n=64)$ - mestrado ( $n=38)$ - doutorado ( $n=28)$ - entrar $(n=35)$ - período $(n=24)$ " representa a trajetória profissional que tem o seu "começar" em algum "curso de graduação". Mas, para chegar até isso, o professor iniciou seu "período" de investimento em sua qualificação ao "entrar" em um "mestrado" e, posteriormente, seguir para o "doutorado". Isso fica claro na fala de (P04): Entrei no mestrado. Aí, defendi em uma semana e na seguinte eu estava dando aula na graduação. No ano seguinte, fui pro doutorado.

O núcleo (4) Atuação se encontra entre os núcleos (1) Professor Universitário e (7) Relação Docente-Discente. O eixo principal é representado por "ficar $(n=83)$ - respeito $(n=22)$ - saber $(n=102)$ - dar aula $(n=96)$ - sala de aula $(n=53)$ - hora $(n=25)$ ". A atuação docente é marcante para a vida do professor, seja no sentido prático de sua profissão, seja de forma subjetiva com relação ao sentido de seu trabalho. Mesmo com todas as demandas, o professor quer "ficar" na docência, pois ali ele reconhece seu espaço, buscando reconhecimento, valorização profissional e "respeito". Sua função envolve a construção do "saber", desenvolvido através de um grande investimento de "horas", que tem na "sala de aula" um de seus espaços de compartilhamento. "Dar aula" é uma importante etapa dessa atuação, muitas vezes marcados por satisfação, mas em outras por desgastes que nada se identificam com o processo de educação que envolve docente-discente. Isso se evidencia na fala de (P07): Em relação a sala de aula... é uma das coisas que eu gosto muito mesmo! Dar aula... É cansativo no meio disso tudo, mas eu fico bem nessa hora.

O núcleo (5) Conflito representa os anseios pessoais em conflito com as demandas práticas enfrentadas pelo professor. Seu eixo principal é: "escrever $(n=24)$ - aula $(n=41)-$ disciplina de graduação - melhor $(n=28)$ - ganhar $(n=29)$ - só $(n=36)$ - universidade pública $(n=120)$ ". Este eixo representa o anseio do professor em se dedicar a "escrever" (produzir pesquisa), mas não conseguir disponibilidade para tal, pois sua sobrevivência são as "aulas" e, consequentemente, as "disciplinas de graduação" que, por sua vez, the proporcionam "melhores" "ganhos" financeiros. Por fim, como sugerem as falas abaixo, 
ele entende que "só" terá condições "melhores" e, principalmente, estáveis em uma "universidade pública".

(P01): Eu tenho dois projetos de extensão que eu não ganho absolutamente nada. Por quê? Porque se eu pedir para ganhar, eu tenho que sair da aula da graduação. Aí a aula paga melhor do que o que eu ganho no projeto.

(P05): A universidade pública me deu exclusividade. Não é só aula. Lá eu ganho para fazer extensão e pesquisa também.

O núcleo (6) Alicerce Docente liga-se ao núcleo (5) Conflito com a coocorrência do termo "pesquisa". Seu eixo de representação é: "estudar $(n=27)$ - precisar $(n=30)-$ atividade $(n=59)$ - instituição $(n=25)$ - pesquisa $(n=30)$ ”. Esse núcleo mostra os principais elementos que apoiam o desenvolvimento das atividades do trabalho docente. Assim, é fundamental que o professor universitário tenha oportunidade de "estudar", pois ele "precisa" se atualizar e buscar por conhecimento. Por sua vez, esses elementos são insumos ao desenvolvimento de sua "atividade" docente. Mas, dependendo da "instituição" ao qual ele esteja vinculado, as oportunidades de dedicação à pesquisa podem não ser prioridade. É interessante notar que "pesquisa", ao ligar-se ao núcleo (5) Conflito, encontra "universidade pública" ao final do eixo. Essa trajetória pode sugerir a falta de recursos do trabalho que o professor sente para desenvolver pesquisas em IES privadas. Muitas das vezes, esses recursos só irão ocorrer quando o professor for vinculado a uma IES pública. Isso se evidencia na fala de (P02): Ter tempo para estudar, elaborar atividades é muito bom, mas precisa de apoio da instituição.

O núcleo (7) Relação Docente-Discente se encontra entre os núcleos (4) Atuação e (8) Sentido do Trabalho. O eixo principal é representado por "aluno de graduação ( $n=143)$ - trabalhar ( $n=117)$ - conseguir $(n=36)$ - significar $(n=76)$ - entender $(n=66)$ - tem que $(n=58)$ ". É possível perceber o movimento que marca a relação do trabalho docentediscente: uma busca pessoal que almeja significar, construir pontes, possibilitar entendimentos e, ao mesmo tempo, lidar com pressões institucionais e com suas próprias cobranças. Isso se evidencia nas falas abaixo:

(P07): Eu tento melhorar cada vez mais a forma de abordar os alunos de graduação, então isso é uma coisa que eu venho trabalhando e assim tento modificar, dar significado no sentido que os alunos percebam, que eles entendam e se envolvam. Às vezes o aluno ainda é um tanto imaturo...

(P01): É difícil conseguir dar conta. A gente tem que fazer tanta coisa. 
P. P.

Professor universitário: percepções acerca das demandas e recursos de seu trabalho

O núcleo (8) Sentido do Trabalho Docente representa a percepção que o professor tem acerca da contribuição de seu trabalho não só para si, mas também para o outro. O sentido do trabalho, como um recurso do trabalho, é uma experiência subjetiva (STEGER, 2016) muito importante para o trabalhador: seu trabalho contribui para sua própria satisfação, mas também colabora para o próximo através de uma atividade nobre, produtiva, com propósito e significado (Allan, Duffy, \& Douglass, 2015; Steger, Dik, \& Duffy, 2012; Steger, Dik, \& Shim, in press).

Nessa perspectiva, a percepção sobre o sentido do trabalho do professor universitário se reflete no eixo "adequado $(n=43)$ - sentir $(n=27)$ - olhar $(n=65)$ - dizer ( $n=73)$ - falar $(n=97)$ - satisfação $(n=61)$ ". O professor se percebe no lugar "adequado", pois é neste espaço onde ele "sente" que seu "dizer", seu "olhar" e seu "falar" constroem um trabalho significativo, com propósito, que o leva a "satisfação", uma vez que contribui para si como educador, mas que também ecoa para o próximo.

(P02): Eu falei. Eu disse o que deveria ser mudado. Sinto que essa é minha missão. Então é uma grande satisfação. Isso mostra o alcance de um objetivo. Para qualquer professor exercer, finalmente, a sua função educadora e não apenas cumprir aquele papel. É muito gratificante.

Por fim, a análise dos núcleos mostrou que, mesmo vivenciando e reconhecendo diversas demandas de obstáculos, o professor universitário encontra sentido em seu trabalho. Ele, o professor, usa de recursos, sejam eles pessoais ou do trabalho, como o resenho, de forma a alcançar melhores desfechos para si, mas também para o outro. Como sugere a fala de (P03), é emaranhado em todo esse contexto que o professor encontra satisfação, mas, também, a falta que o impulsiona a continuar: Apesar da minha fala direcionar para uma imensa satisfação, não existe a satisfação ampla em nada que se faça. Existem sempre as questões administrativas, contratempos, percalços... Mas, entre a insatisfação em não conseguir fazer tudo o que se deseja, mas fazer tudo o que você pode, nesse país com todo esse contexto político e econômico, já é algo tão bom, que a gente deve ficar muito satisfeito com o pouco que se tem. Pode parecer que eu só falei coisas boas. Não. Tem muita coisa ruim. Mas eu estou muito satisfeito com o que tenho e com o que eu tenho conseguido. Mais do que qualquer outra coisa: fazer da universidade uma coisa boa. E dessa satisfação de conseguir fazer uma coisa boa e ter resultado é que vem essa minha fala. 


\section{CONSIDERAÇOEES FINAIS}

O presente estudo procurou explorar as percepções do professor universitário sobre a reestruturação de seu trabalho e suas implicações para sua vida laboral e pessoal. Para tal, explorou-se a compreensão do professor acerca dos recursos (pessoais e do trabalho), demandas, investimentos para redesenho do trabalho e suas percepções sobre o sentido de seu trabalho.

Foi possível notar o forte envolvimento e investimento que o professor universitário tem em sua profissão. Porém, a nova organização do trabalho tem levado a desgastes pelo desequilíbrio entre demandas e recursos. Constatou-se que a utilização de recursos do trabalho e recursos pessoais, como a autoeficácia ocupacional, as ações de redesenho do trabalho e o sentido do trabalho foram fatores importantes para diminuir demandas, como também proteger a saúde docente. Em relação as limitações desse estudo, sugere-se a ampliação da amostra, bem como a diversificação para outros Estados brasileiros de forma a aprofundar o entendimento sobre essa temática.

\section{REFERÉNCIAS}

ALLAN, B. A.; DUFFY, R. D.; DOUGLASS, R. Meaning in life and work: A developmental perspective. The Journal of Positive Psychology, v. 10, n. 4, p. 323-331, 4 jul. 2015.

BAKKER, A. B.; DEMEROUTI, E. La teoría de las demandas y los recursos laborales. Revista de Psicología del Trabajo y de las Organizaciones, v. 29, n. 3, p. 107-115, dez. 2013.

BAKKER, A. B.; DEMEROUTI, E. Job Demands-Resources Theory. In: CHEN, P. Y.; COOPER, C. L. (Eds.). . Work and Wellbeing: Wellbeing: A Complete Reference Guide. Chichester, UK: John Wiley \& Sons, Ltd, 2014. p. 1-28.

BAKKER, A. B.; DEMEROUTI, E. Job demands-resources theory: taking stock and looking forward. Journal of Occupational Health Psychology, v. 22, n. 3, p. 273-285, jul. 2017.

BAKKER, A. B.; DEMEROUTI, E. Multiple levels in job demands-resources theory: Implications for employee well-being and performance. In: Handbook of well-being. Salt Lake City, UT: DEF Publishers, 2018. p. 1-13.

BAKKER, A. B.; DEMEROUTI, E.; SANZ-VERGEL, A. I. Burnout and work engagement: The JD-R approach. Annual Review of Organizational Psychology and

Organizational Behavior, v. 1, n. 1, p. 389-411, 21 mar. 2014. 
CAMARGO, B. V.; JUSTO, A. M. IRAMUTEQ: um software gratuito para análise de dados textuais. Temas em Psicologia, v. 21, n. 2, p. 513-518, 2013.

CARLOTTO, M. S. et al. O papel mediador da autoeficácia na relação entre a sobrecarga de trabalho e as dimensões de Burnout em professores. Psico-USF, v. 20, n. 1, p. 13-23, abr. 2015.

CONTRERAS, J. Autonomia de professores. Traducao Sandra Trabucco Valenzuela. São Paulo: Cortez, 2012.

CRAWFORD, E. R.; LEPINE, J. A.; RICH, B. L. Linking job demands and resources to employee engagement and burnout: $A$ theoretical extension and meta-analytic test. Journal of Applied Psychology, v. 95, n. 5, p. 834-848, 2010.

DALAGASPERINA, P.; KIELING MONTEIRO, J. Estresse e docência: um estudo no ensino superior privado. Revista Subjetividades, v. 16, n. 1, p. 37-51, 29 abr. 2016.

DEMEROUTI, E. et al. The job demands-resources model of burnout. Journal of Applied Psychology, v. 86, n. 3, p. 499-512, 2001.

FERREIRA, L. C. M. Crenças de autoeficácia docente, satisfação com o trabalho e adoecimento. Psicologia: Ensino \& Formação, v. 5, n. 2, p. 19-37, 2014.

HAAS, C. M.; PARDO, R. DA S. Programa Universidade para Todos (PROUNI): efeitos financeiros em uma instituição de educação superior privada. Avaliação: Revista da Avaliação da Educação Superior (Campinas), v. 22, n. 3, p. 718-740, dez. 2017.

HARRIS, K. J.; KACMAR, K. M.; ZIVNUSKA, S. An investigation of abusive supervision as a predictor of performance and the meaning of work as a moderator of the relationship.

The Leadership Quarterly, v. 18, n. 3, p. 252-263, jun. 2007.

Lei $\mathrm{n}^{\circ}$ 11.096, de 13 de janeiro de 2005. Institui o Programa Universidade para Todos PROUNI, regula a atuação de entidades beneficentes de assistência social no ensino superior; altera a Lei no 10.891, de 9 de julho de 2004, e dá outras providências: [s.n.].

MAGALHÃES, S. M. O. Trabalho, pesquisa e ensino: tensões e desafios para a docência no ensino superior. Psicologia: Ensino \& Formação, v. 4, n. 1, p. 60-78, 2013.

MARCHAND, P.; RATINAUD, P. L'analyse de similitude appliquée aux corpus textuels : les primaires socialistes pour l'élection présidentielle française. In: Actes des 11èmes Journées Internationales d'Analyse des Données Textuelles (JADT). [s.I: s.n.]. p. 687-699.

PRATT, M. G.; ASHFORTH, B. E. Fostering meaningfulness in working and at work: An identity perspective. Positive organizational scholarship: Foundations of a new discipline, n. December, p. 309-327, 2003.

RIGOTTI, T.; SCHYNS, B.; MOHR, G. A Short Version of the Occupational Self-Efficacy Scale: Structural and Construct Validity Across Five Countries. Journal of Career Assessment, v. 16, n. 2, p. 238-255, maio 2008. 
SCHAUFELI, W. B. Heavy work investment, personality and organizational climate. Journal of Managerial Psychology, v. 31, n. 6, p. 1057-1073, 2016.

SCHAUFELI, W. B. Applying the Job Demands-Resources model: A 'how to' guide to measuring and tackling work engagement and burnout. Organizational Dynamics, v. 46, n. 2, p. 120-132, abr. 2017.

SCHAUFELI, W. B.; TARIS, T. W. A Critical review of the Job Demands-Resources Model: implications for improving work and health. In: BAUER, G. F.; HÄMMIG, O. (Eds.). . Bridging Occupational, Organizational and Public Health. Dordrecht: Springer Netherlands, 2014. v. 9789400756p. 43-68.

SCHÖNFELD, P. et al. The effects of daily stress on positive and negative mental health: mediation through self-efficacy. International Journal of Clinical and Health Psychology, v. 16, n. 1, p. 1-10, jan. 2016.

SOUZA, I. R. DE; SANTOS, M. E. R. DOS; ALMEIDA, I. N. S. DE. Mal-estar doente: a saúde dos professores nos dias atuais. Revista Humanidades e Inovação, v. 4, n. 2, p. 84-94, 2016.

SOUZA, K. R. et al. A nova organização do trabalho na universidade pública: consequências coletivas da precarização na saúde dos docentes. Ciência \& Saúde Coletiva, v. 22, n. 11, p. 3667-3676, 2017.

SOUZA, M. R. DE A.; MENEZES, M. Programa Universidade para Todos (PROUNI): quem ganha o quê, como e quando? Ensaio: Avaliação e Políticas Públicas em Educação, v. 22, n. 84, p. 609-633, 2014.

STEGER, M. F. Creating Meaning and Purpose at Work. The Wiley Blackwell Handbook of the Psychology of Positivity and Strengths-Based Approaches at Work, $n$. November 2016, p. 60-81, 2016.

STEGER, M. F.; DIK, B. J.; DUFFY, R. D. Measuring Meaningful Work. Journal of Career Assessment, v. 20, n. 3, p. 322-337, 19 ago. 2012.

STEGER, M. F.; DIK, B. J.; SHIM, Y. Measuring Satisfaction and Meaning at Work. In: LOPEZ, S. J. (Ed.). . The Oxford handbook of positive psychology assessment. 2. ed. Oxford, England: Oxford University Press, [s.d.].

TIMS, M.; DERKS, D.; BAKKER, A. B. Job crafting and its relationships with person-job fit and meaningfulness: A three-wave study. Journal of Vocational Behavior, v. 92, p. 4453, 2016.

VAN WINGERDEN, J.; DERKS, D.; BAKKER, A. B. The impact of personal resources and job crafting interventions on work engagement and performance. Human Resource Management, v. 56, n. 1, p. 51-67, 2017.

WRZESNIEWSKI, A.; DUTTON, J. E. Crafting a job: revisioning employees as active crafters of their work. Academy of Management Review, v. 26, n. 2, p. 179-201, abr. 2001. 